\title{
EFFECT OF SPECIMEN SIZE OF STATIC COMPRESSIVE TEST ON THE DYNAMIC INCREASE FACTOR OF CONCRETE COMPRESSIVE STRENGTH
}

\author{
SANGHO LEE, CHUNGHYEON KIM \& JAE-YEOL CHO \\ Department of Civil and Environmental Engineering, Seoul National University, South Korea
}

\begin{abstract}
Compressive strength of concrete increases as the strain rate increases, so this rate effect should be considered when conducting finite element analysis to evaluate behavior of structure under high strain rate. Accordingly, numerous split Hopkinson pressure bar (SHPB) tests have been conducted to evaluate dynamic strength at high strain rate. However, there is no standard test method for SHPB test. As a result, researchers have performed SHPB test for concrete and analyzed the results as their own method. Especially, since various sizes of specimen have been used for SHPB test, various shapes and sizes of specimens have been used for static compressive test to obtain static strength. In this study, SHPB test for concrete specimen was performed. Then, finite element analyses of concrete SHPB test were conducted using two types of dynamic increase factor (DIF) obtained from two types of static strengths in order to find out which static strength is appropriate to obtain DIF; one is static strength from standard cylinder specimen, and the other is static strength from specimen of same diameter as that of specimen of SHPB test. Then, the results were compared to each other. The comparison showed that DIF obtained from standard cylinder test is more valid than DIF obtained from specimen of same diameter as SHPB test specimen.

Keywords: dynamic increase factor, split Hopkinson pressure bar, rate effect, static strength.
\end{abstract}

\section{INTRODUCTION}

It is well known that compressive and tensile strength of concrete increases as strain rate increases. This effect has been called the rate effect on concrete strength, and in order to consider the rate effect in finite element analysis and design for concrete structures under extreme events, dynamic increase factor (DIF) has been used. DIF is defined as the ratio of dynamic strength to static strength, and DIF has been investigated performing various high rate material tests. Especially, to investigate DIF of compressive strength, the most popular one of high rate material tests is split Hopkinson pressure bar (SHPB) test.

Accordingly, DIF of concrete compressive strength has been investigated conducting numerous SHPB tests [1]-[6]. However, there is no standard test method for SHPB test. As a result, researchers have conducted SHPB test for concrete and analysed the results as their own method. Especially, because various shapes and sizes of specimens have been used to SHPB test, various shapes and sizes of specimens have been used to static strength test [1][6]. However, concrete static strength is affected by size and shape of specimen of static strength test, so it is necessary to clarify how to obtain static strength to calculate DIF [4].

In this study, concrete SHPB tests were conducted and the two types of DIFs were obtained; one was calculated with static strength of D150×H300 standard cylinder specimen, and the other was determined from static strength of specimen with same diameter of specimen used in SHPB test. Then in order to determine which static strength should be used to calculate DIF, the finite element analyses for the SHPB test were conducted applying the two DIFs. 


\section{STATIC COMPRESSIVE STRENGTH TEST AND SHPB TEST PROGAMS}

\subsection{Static compressive strength test program and results}

Static strength tests were performed for three sizes of specimens; D50 $\times$ H100, D75 $\times$ H150, and D150 $\times$ H300 cylinder specimens. In order to compare the static strength at the same strain rate $10^{-5} \mathrm{~s}^{-1}$, the displacement rate of load plate was set up as $0.001,0.0015$, and 0.003 $\mathrm{mm} / \mathrm{s}$, respectively. Also, three kinds of mix proportions were used in the tests as shown in Table 1. Maximum size of coarse aggregate was $13 \mathrm{~mm}$ because specimens of SHPB test have small dimension. For each case, three specimens were tested at the 28-day age, and the results were averaged. Table 2 shows the static strength test results for each specimen size and each mix proportion. It is known generally that smaller specimen shows higher compressive strength. However, this common sense can be applied in the case that the same displacement ratio was used to both small and large specimens. In this study, since the displacement rate was set differently according to specimen dimension to make strain rate constant in static test, the common sense was not applied.

\subsection{SHPB test program and results}

\subsubsection{SHPB test program}

For each mix proportion in Table 1, four sizes of specimen were prepared for SHPB tests; diameter 50 and $75 \mathrm{~mm}$, and L/D ratio 0.5 and 1 as shown in Fig. 1. Also, six different conditions of strain rate were applied to each mix proportion and each size of specimen. To control strain rate, various lengths of striker bars and impact velocities were used as shown in Table 3.

Diameter $76.2 \mathrm{~mm}$ SHPB apparatus was used, and the length of incident and transmitted bars is $5.5 \mathrm{~m}$. To satisfy dynamic equilibrium state of specimens during the tests, annular pulse shapers, which were suggested by Heard et al. [7], were applied to the tests. Petroleum jelly was applied to the surfaces of specimens to minimize the frictional effect.

Table 1: Concrete mix proportions.

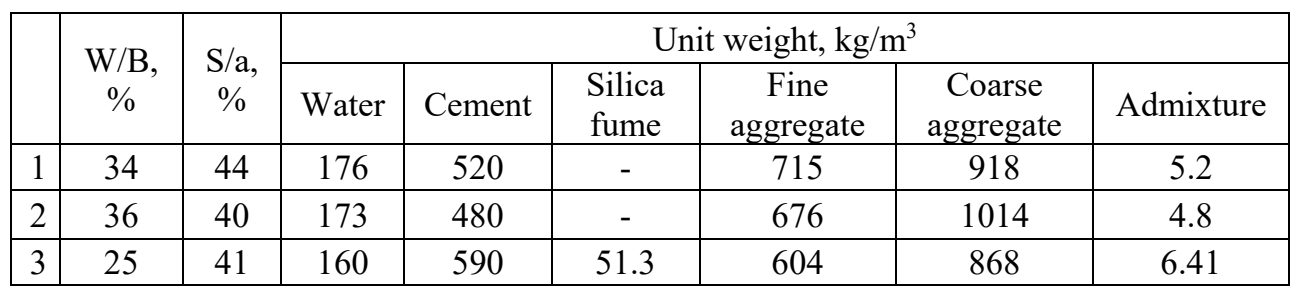

Table 2: Results of static compressive strength test.

\begin{tabular}{|c|c|c|c|}
\hline \multirow{2}{*}{$\begin{array}{c}\text { Mix } \\
\text { number }\end{array}$} & \multicolumn{3}{|c|}{ Static compressive strength, MPa } \\
\cline { 2 - 4 } & D50×H100 & D75×H150 & D150 $\times$ H300 \\
\hline 1 & 36 & 44 & 52 \\
\hline 2 & 43 & 53 & 61 \\
\hline 3 & 69 & 79 & 85 \\
\hline
\end{tabular}




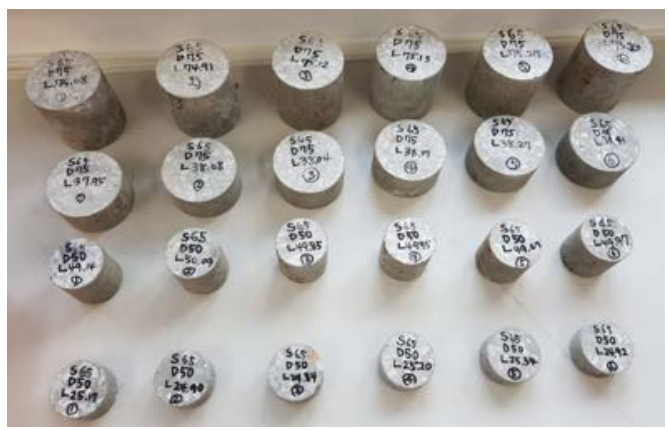

Figure 1: SHPB test specimens.

Table 3: Striker lengths and impact velocities.

\begin{tabular}{|c|c|}
\hline Variables & Range \\
\hline Striker length, $\mathrm{mm}$ & $200-600$ \\
\hline Impact velocity, $\mathrm{m} / \mathrm{s}$ & $12-20$ \\
\hline
\end{tabular}

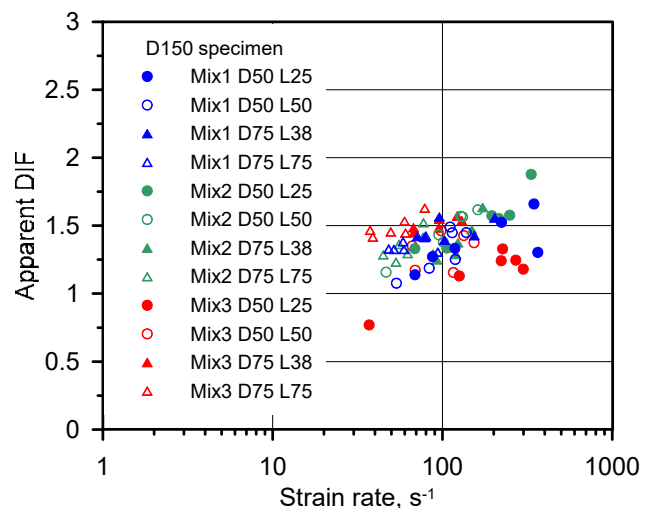

(a)

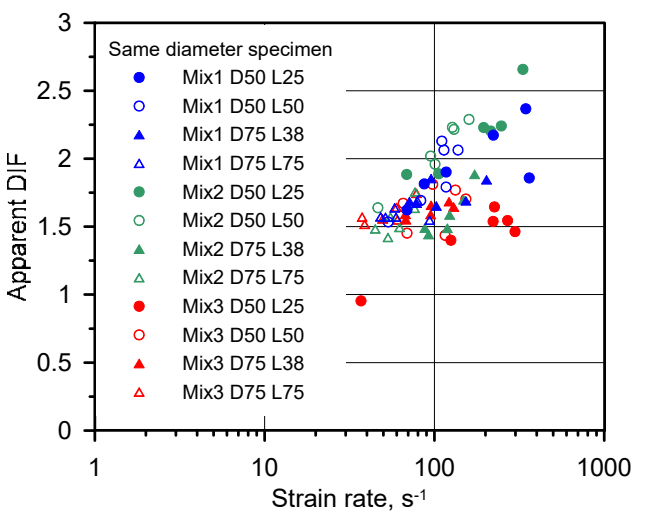

(b)

Figure 2: Apparent DIF. (a) Apparent DIF obtained from static strength of D150 $\times$ H300 specimen; (b) Apparent DIF obtained from static strength of the same diameter specimen.

\subsubsection{SHPB test results}

The dynamic strength obtained from SHPB test was divided by two types of static strengths; one is static strength of $\mathrm{D} 150 \times \mathrm{H} 300$ cylinder specimen, and the other is static strength of cylinder specimen of the same diameter as specimen of SHPB test. Therefore, two types of apparent DIFs were obtained as test results as shown in Fig. 2.

For each DIF case, pure rate DIF was obtained by eliminating inertia effects from apparent DIF in accordance with Lee et al. [5]. Eqns (1) and (2) indicate the pure rate DIFs from D150 $\times$ H300 specimen and the same diameter specimen, respectively. 


$$
\begin{aligned}
D I F_{D 150} & =\left(\frac{\dot{\epsilon}_{S}}{10^{-5}}\right)^{0.0147} \\
D I F_{S D} & =\left(\frac{\dot{\epsilon}_{S}}{10^{-5}}\right)^{0.0240}
\end{aligned}
$$

\section{FINITE ELEMENT ANALYSES FOR THE SHPB TESTS}

\subsection{Finite element analysis program and results}

To determine which static strength should be used to calculate DIF, finite element analyses for the SHPB tests were conducted using the two DIFs, eqns (1) and (2). LS-DYNA was used as finite element analysis program, as shown in Fig. 3. As material model of bar components, linear elastic model was adopted because bar components remain elastic state during test. For specimen, concrete damage model (MAT072R) was adopted as material model, and mesh size was determined as $5 \mathrm{~mm}$. Also, the static strength of standard cylinder specimen was used as the compressive strength of specimen in the material model. 8-node solid element was applied for bar components and specimen, and 1-point gauss integration was used. Instead of modelling striker bar and pulse shaper, the incident waves measured from the test were converted into equivalent nodal forces and were applied to the end of the incident bar. As results of the analyses, stresses of the incident and transmitted bars were obtained, and dynamic strength was calculated using one-dimensional stress wave theory. Then, apparent strength ratio was calculated using eqn (3), which was introduced to evaluate predictive accuracy of DIF by Lee et al. [5]. If apparent strength ratio is close to 1, it means that the corresponding DIF gives good prediction. On the other hand, the ratio larger than 1 means that the corresponding DIF overestimates the real apparent dynamic strength

$$
\text { Apparent strength ratio }=\frac{\text { apparent dyanmic strength from } F E A}{\text { apparent dyanmic strength from } S H P B \text { test }} .
$$

Fig. 4 shows the apparent strength ratio for each DIF, and Table 4 indicate the mean and the coefficient of variation of apparent strength ratio for all SHPB test.

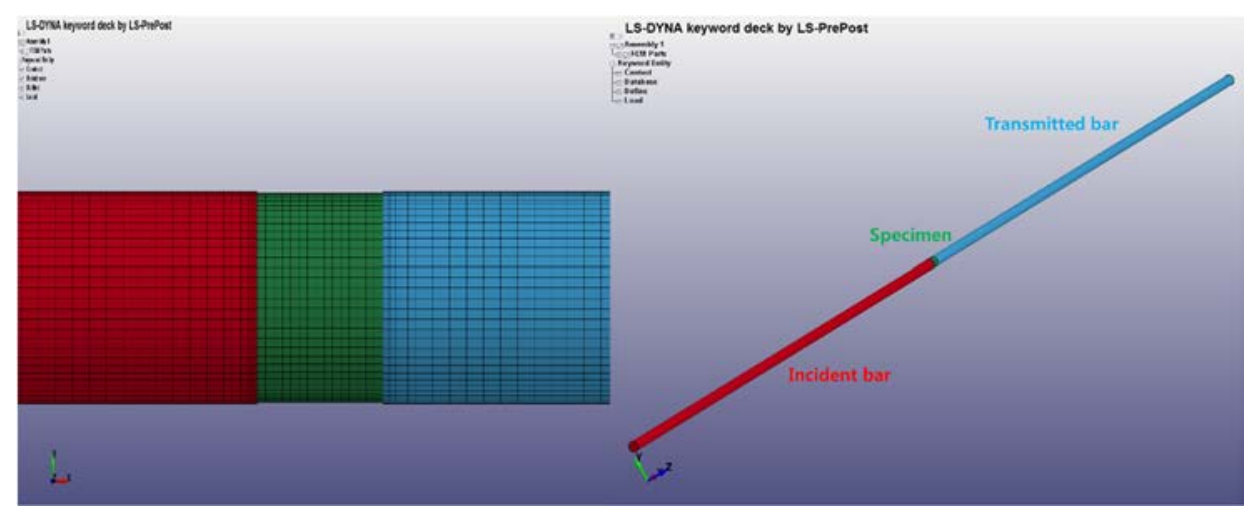

Figure 3: Finite element analysis model of SHPB test. 


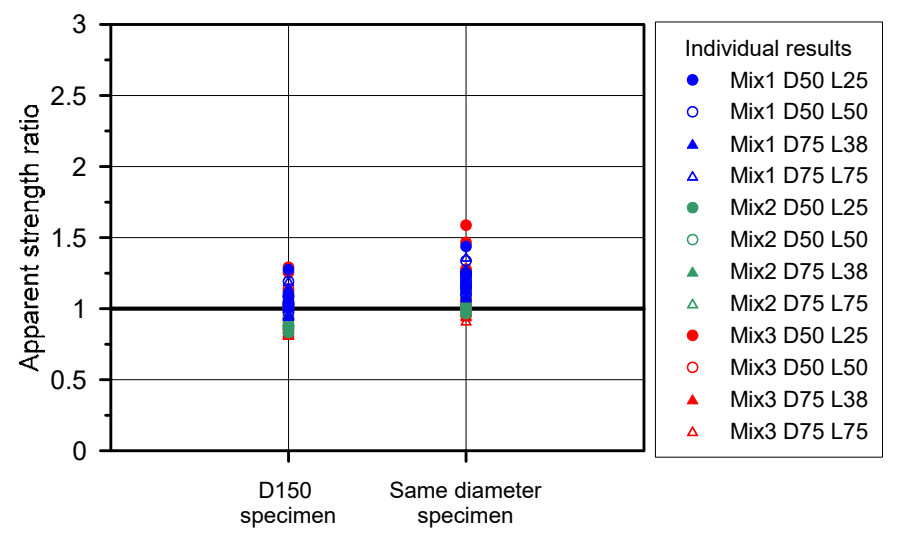

Dynamic Increase Factor

Figure 4: Apparent strength ratio for each DIF.

Table 4: Statistics of apparent strength ratio for both DIFs.

\begin{tabular}{|c|c|c|}
\hline & $\begin{array}{c}\text { D150 } \times \mathrm{H} 300 \\
\text { specimen }\end{array}$ & $\begin{array}{c}\text { Same diameter } \\
\text { specimen }\end{array}$ \\
\hline Mean & 1.00 & 1.15 \\
\hline C.O.V. & 0.11 & 0.11 \\
\hline
\end{tabular}

\subsection{Discussion}

As known from Fig. 3 and Table 4, the DIF from standard cylinder specimen gave better predictions than the DIF from the same diameter specimen. Static strength of same diameter specimen was evaluated much lower than strength of standard cylinder specimen. Because of the underestimation of static strength, the DIF from the same diameter specimen was evaluated higher than DIF form standard cylinder specimen. Small diameter specimen is not standard specimen to determine static strength, so static strength cannot be evaluated appropriately.

\section{CONCLUSION}

In this study, the effect of specimen of static strength test on DIF of concrete compressive strength was investigated. Furthermore, following conclusions were derived.

- Static strength cannot be evaluated appropriately from small diameter specimen.

- Static strength of standard cylinder specimen is more appropriate to be used to calculation of DIF than static strength of specimen with the same diameter as diameter of specimen of SHPB test.

\section{ACKNOWLEDGEMENTS}

This work was supported by the Infrastructure and Transportation Technology Advancement Research Program funded by the Ministry of Land, Infrastructure and Transport of Korean 
government [grant number 18CTAP-C129906-02]; the National Research Foundation of Korea (NRF) grant funded by the Korea government [grant number NRF2017R1A2B2003640]; the BK21 PLUS research program of the National Research Foundation of Korea.

\section{REFERENCES}

[1] Ross, C.A., Tedesco, J.W. \& Kuennen, S.T., Effects of strain rate on concrete strength. ACI Materials Journal, 92(1), pp. 37-45, 1995.

[2] Grote, D., Park, S. \& Zhou, M., Dynamic behavior of concrete at high strain rates and pressures: I. experimental characterization. International Journal of Impact Engineering, 25(9), pp. 869-886, 2001.

[3] Zhang, M., Wu, H.J., Li, Q.M. \& Huang, F.L., Further investigation on the dynamic compressive strength enhancement of concrete-like materials based on split Hopkinson pressure bar tests. Part I: experiments. International Journal of Impact Engineering, 36(12), pp. 1327-1334, 2009.

[4] Zhang, M.-H., Quek, S.T. \& Wang, S., Effect of specimen size on static strength and dynamic increase factor of high-strength concrete from SHPB test. Journal of Testing and Evaluation, 39(5), pp. 1-10, 2011.

[5] Lee, S., Kim, K.-M., Park, J. \& Cho, J.-Y., Pure rate effect on the concrete compressive strength in the split Hopkinson pressure bar test. International Journal of Impact Engineering, 113, pp. 191-202, 2018.

[6] Li, M., Hao, H., Shi, Y. \& Hao, Y., Specimen shape and size effects on the concrete compressive strength under static and dynamic tests. Construction and Building Materials, 161, pp. 84-93, 2018.

[7] Heard, W.F., Martin, B.E., Nie, X., Slawson, T. \& Basu, P.K., Annular pulse shaping technique for large-diameter Kolsky bar experiments on concrete. Experimental Mechanics, 54(8), pp. 1343-1354, 2014. 